\title{
Fabrication of Microbolometer Arrays Based on Polymorphous Silicon-Germanium
}

\author{
Ricardo Jimenez ${ }^{1}$, Mario Moreno ${ }^{1, *}$, Alfonso Torres ${ }^{1}$, Alfredo Morales ${ }^{1}$, Arturo Ponce ${ }^{1,2}$, \\ Daniel Ferrusca ${ }^{1}$, Jose Rangel-Magdaleno ${ }^{1}{ }^{\circledR}$, Jorge Castro-Ramos ${ }^{1}$, Julio Hernandez-Perez ${ }^{1}$ and \\ Eduardo Cano ${ }^{1}$ \\ 1 Electronics Group, National Institute of Astrophysics, Optics and Electronics, Puebla 72840, Mexico; \\ rjzavala@inaoep.mx (R.J.); atorres@inaoep.mx (A.T.); alfredom@inaoep.mx (A.M.); aponce@inaoep.mx (A.P.); \\ dferrus@inaoep.mx (D.F.); jrangel@inaoep.mx (J.R.-M.); jcastro@inaoep.mx (J.C.-R.); \\ julio.hernandez@inaoep.mx (J.H.-P.); eduardo.canohe@my.uvm.edu.mx (E.C.) \\ 2 Department of Physics and Astronomy, University of Texas at San Antonio, San Antonio, TX 78249, USA \\ * Correspondence: mmoreno@inaoep.mx
}

Received: 30 March 2020; Accepted: 24 April 2020; Published: 9 May 2020

check for updates

\begin{abstract}
This work reports the development of arrays of infrared sensors (microbolometers) using a hydrogenated polymorphous silicon-germanium alloy (pm-Si $\left.\mathrm{Ge}_{1-x}: \mathrm{H}\right)$. Basically, polymorphous semiconductors consist of an amorphous semiconductor matrix with embedded nanocrystals of about 2-3 nm. The pm-Si $\mathrm{Ge}_{1-x}: \mathrm{H}$ alloy studied has a high temperature coefficient of resistance (TCR) of $4.08 \% / \mathrm{K}$ and conductivity of $1.5 \times 10^{-5} \mathrm{~S} \cdot \mathrm{cm}^{-1}$. Deposition of thermosensing film was made by plasma-enhanced chemical vapor deposition (PECVD) at $200{ }^{\circ} \mathrm{C}$, while the area of the devices is $50 \times 50 \mu \mathrm{m}^{2}$ with a fill factor of $81 \%$. Finally, an array of $19 \times 20$ microbolometers was packaged for electrical characterization. Voltage responsivity values were obtained in the range of $4 \times 10^{4} \mathrm{~V} / \mathrm{W}$ and detectivity around $2 \times 10^{7} \mathrm{~cm} \cdot \mathrm{Hz}^{1 / 2} / \mathrm{W}$ with a polarization current of $70 \mu \mathrm{A}$ at a chopper frequency of $30 \mathrm{~Hz}$. A minimum value of $2 \times 10^{-10} \mathrm{~W} / \mathrm{Hz}^{1 / 2}$ noise equivalent power was obtained at room temperature. In addition, it was found that all the tested devices responded to incident infrared radiation, proving that the structure and mechanical stability are excellent.
\end{abstract}

Keywords: infrared; sensor; microbolometer; array; polymorphous; silicon; germanium; plasmaenhanced chemical vapor deposition

\section{Introduction}

Semiconductor materials with characteristics of low resistivity and high temperature coefficient of resistance (TCR) are important for detection of infrared radiation by uncooled microbolometers, which are widely used in the range of $8-12 \mu \mathrm{m}$, known as LWIR (long-wave infrared). A microbolometer is a thermal detector where a resistive membrane absorbs infrared radiation, which increases its temperature. For semiconductor materials, the increase in temperature reduces the resistance of the membrane and the measurement of the change of resistance is the output of the sensor. A high TCR is desirable to increase the sensitivity of the device or maintaining it when it is desired to reduce the pixel area. On the other hand, a low resistivity makes it easier to read the pixels with the associated ROIC (readout integrated circuit). In addition, the resistivity of the material directly influences the $1 / \mathrm{f}$ noise and consequently the performance of the devices.

In relation to the electrical characteristics described above, several materials have been studied for their application as thermosensing films, including carbon nanotubes and other organic compounds with TCR values of about $2.1 \%-3.1 \% / \mathrm{K}$ [1-3], poly-SiGe $(0.68 \%-2 \% / \mathrm{K})$ [4], Y-Ba-Cu-O $(\sim 3.3 \% / \mathrm{K})[5]$, 
metal films $\mathrm{Pt}(\sim 0.14 \% / \mathrm{K})[6]$, Ti $(\sim 0.35 \% / \mathrm{K})$ [7,8]; as well $\mathrm{ZnO}$ has shown high TCR $(\sim 10.4 \% / \mathrm{K})$ in thin films, but without reported experimental results on devices [9].

At the present time, vanadium oxide $\left(\mathrm{VO}_{\mathrm{x}}\right)(\sim 2 \% / \mathrm{K})[10-16]$ and doped amorphous silicon (a-Si) with TCR values of $2 \%-5 \% / K$ [17-22] are the two main materials used as thermosensing films in commercial microbolometers. However, amorphous silicon, usually doped with boron, is replacing vanadium oxide in large commercial arrays. The reason is the full silicon complementary metal oxide semiconductor (CMOS) processes compatibility and the larger TCR of amorphous silicon. This means that large arrays can be fabricated in standard silicon CMOS facilities, and moreover, those arrays contain devices with better performance characteristics.

In this work, we study the implementation in microbolometer arrays of a hydrogenated polymorphous

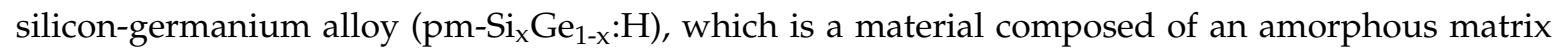
with embedded nanocrystals in the range of 2-3 $\mathrm{nm}$ [23]. The presence of nanocrystals reduces the density of states, improving the transport properties and the stability of the material against radiation-induced degradation (Staebler-Wronski effect) [24]. This was confirmed with the results of aged polymorphous silicon (pm-Si:H) solar cells by light-soaking [25]. In pm-Six $\mathrm{Ge}_{1-\mathrm{x}}: \mathrm{H}$, the TCR can be easily modified with the silicon/germanium ratio of the alloy, and as a consequence the $1 / \mathrm{f}$ noise is also modified [26,27]. This novel material is deposited by plasma-enhanced chemical vapor deposition (PECVD) at low temperature and pattern definition can be performed by dry-etching techniques, which are conventional steps in integrated circuits processing; moreover, their TCR values are larger than those obtained in doped amorphous silicon. As a result, $\mathrm{pm}-\mathrm{Si}_{\mathrm{x}} \mathrm{Ge}_{1-\mathrm{x}}: \mathrm{H}$ is a material with full CMOS processes compatibility and can also be synthesized at low temperatures, making it ideal for microbolometer implementation.

In previous work, titanium (Ti) electrodes were on the top of the membrane [28,29], however, there were problems of stress mismatching between $\mathrm{Ti}$ and $\mathrm{pm}-\mathrm{Si}_{\mathrm{x}} \mathrm{Ge}_{1-\mathrm{x}}: \mathrm{H}$. Now we have decided to replace the coplanar electrodes with Ti studs; in addition, an array of microbolometers with pixel area of $50 \times 50 \mu \mathrm{m}^{2}$ was fabricated in order to study the stability of the structures and analyze their performance quality.

\section{Materials and Methods}

\subsection{Preparation Method of the Thermosensing Film}

Deposition of $\mathrm{pm}-\mathrm{Si}_{\mathrm{x}} \mathrm{Ge}_{1-\mathrm{x}}: \mathrm{H}$ was made in a plasma-enhanced chemical vapor deposition (PECVD) reactor AMP-3300 from Applied Materials, Inc., Santa Clara, CA, USA, working at $110 \mathrm{kHz}$. A mixture of silane $\left(\mathrm{SiH}_{4}\right)$ and germane $\left(\mathrm{GeH}_{4}\right)$ gases were diluted in hydrogen with a ratio of 1:20. Nanocrystal formation is promoted when plasma conditions are close to powder regime [30], in that sense we set a relatively high pressure inside the chamber. The whole set of conditions is listed in Table 1.

Table 1. Deposition parameters for the $\mathrm{pm}-\mathrm{Si}_{\mathrm{x}} \mathrm{Ge}_{1-\mathrm{x}}: \mathrm{H}$ layer.

\begin{tabular}{cccccc}
\hline $\mathrm{GeH}_{\mathbf{4}}(\mathbf{s c c m})$ & $\mathrm{SiH}_{\mathbf{4}}(\mathbf{s c c m})$ & $\mathbf{H}_{\mathbf{2}}(\mathbf{s c c m})$ & Pressure (Torr) & Power $\left(\mathrm{mW} / \mathrm{cm}^{2}\right)$ & Temperature $\left({ }^{\circ} \mathrm{C}\right)$ \\
\hline 30 & 20 & 1000 & 1.2 & 90 & 200 \\
\hline
\end{tabular}

\subsection{Temperature Dependence of Conductivity}

In order to measure dark conductivity as a function of temperature $\sigma(T)$, a pm-Si $\mathrm{Ge}_{1-x}: \mathrm{H}$ film was deposited on top of coplanar titanium electrodes using Corning Glass 2947 as a substrate. The geometry of the electrodes was $300 \mathrm{~nm}$ thick, $9.5 \mathrm{~mm}$ long, and separated by $2 \mathrm{~mm} . \sigma(T)$ of the films was measured in the range of 300-400 K inside a vacuum thermostat VPF-100 from Janis Research Company, LLC, Woburn, M.A. USA, at $15 \mathrm{mTorr}$ in steps of $10 \mathrm{~K}$, while a ramp of $5 \mathrm{~K} / \mathrm{min}$ was employed. At every point, the sample was allowed to thermalize for $3 \mathrm{~min}$ before each measurement. As humidity can play a major role in conductivity measurements [31], two heating ramps were carried out, one to desorb 
humidity and the second for data collection. The conductivity in $\mathrm{pm}-\mathrm{Si}_{\mathrm{x}} \mathrm{Ge}_{1-\mathrm{x}}$ :H shows a thermally activated Arrhenius behavior, which is related to activation energy $\left(E_{a}\right)$ through Equation (1), where $k$ is the Boltzmann constant and $\sigma_{0}$ the conductivity prefactor [19].

$$
\sigma(T)=\sigma_{0} \exp \left(-E_{a} / k T\right) .
$$

Solving for $E_{a}$ to fit the experimental data with a straight line, gives Equation (2):

$$
\operatorname{Ln}(\sigma)=\operatorname{Ln}\left(\sigma_{0}\right)-E_{a} / k T \text {. }
$$

The slope of the line gives $E_{a}$ and the TCR is finally calculated using Equation (3):

$$
T C R=\left(-E_{a} / k T^{2}\right) \times 100 .
$$

Polymorphous silicon-germanium, like many semiconductors, exhibits a negative TCR (its resistance decreases with temperature), although for convenience the absolute value will be mentioned unless otherwise indicated.

Figure 1a shows an Arrhenius plot of conductivity as a function of temperature for the film deposited under the conditions given in Table 1. From that plot, the slope of the line gives us $E_{a}=0.317 \mathrm{eV}$, which corresponds to a high $T C R=4.08 \% / \mathrm{K}$ and a room temperature conductivity of $\sigma_{R T}$ $=1.5 \times 10^{-5} \mathrm{~S} \cdot \mathrm{cm}^{-1}$. Figure $1 \mathrm{~b}$ shows a high-resolution field emission SEM (FE-SEM) image of the $\mathrm{pm}-\mathrm{Si}_{\mathrm{x}} \mathrm{Ge}_{1-\mathrm{x}}: \mathrm{H}$ membrane surface, where several silicon-germanium nanoclusters are observed.

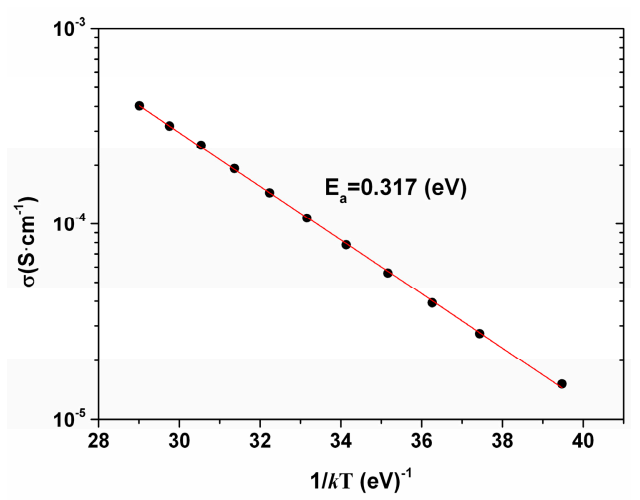

(a)

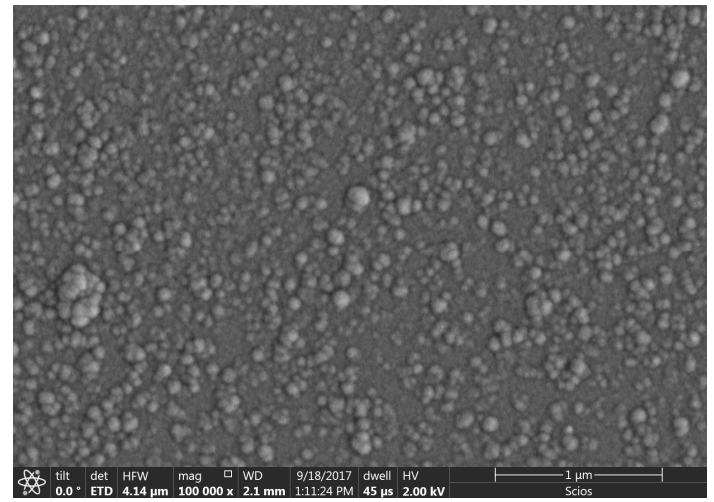

(b)

Figure 1. (a) Temperature dependence of conductivity for the pm-Si $\mathrm{Ge}_{\mathrm{x}-\mathrm{x}}: \mathrm{H}$ film. (b) High-resolution

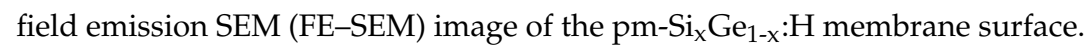

\subsection{Microbolometer Fabrication}

The fabrication of the microbolometer array started with an oxidized silicon wafer, followed by the deposition of $600 \mathrm{~nm}$ of aluminum (Al) pad by e-beam evaporation, and defined by lithography and wet etching in Al-etch solution $\left(80 \% \mathrm{H}_{3} \mathrm{PO}_{4}+5 \% \mathrm{HNO}_{3}+5 \% \mathrm{CH}_{3} \mathrm{COOH}+10 \% \mathrm{H}_{2} \mathrm{O}\right.$ at $40{ }^{\circ} \mathrm{C}$, $10 \mathrm{~min})$. Figure 2 shows the fabrication process. 


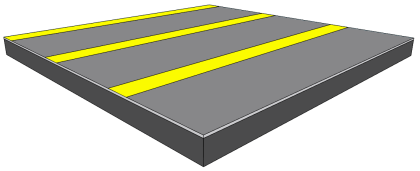

(a)

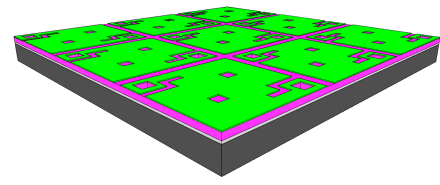

(d)

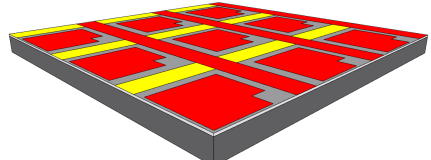

(b)

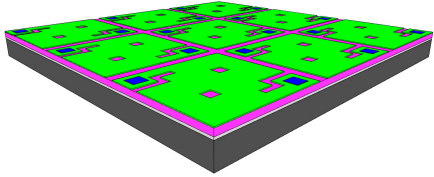

(e)

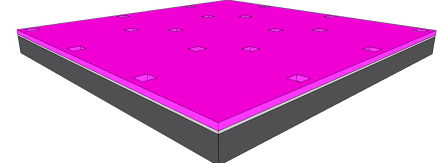

(c)

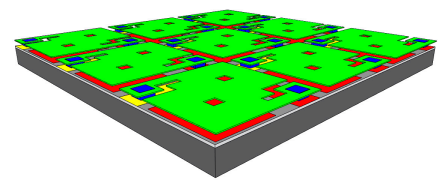

(f)

Figure 2. Fabrication process flow: (a) aluminum deposition and patterning (columns); (b) after deposition of the double layer of dielectric, a second layer deposition of aluminum (rows and mirror) followed; (c) polyimide deposition and opening of holes for contacts; (d) pm-Si $\mathrm{Se}_{1-\mathrm{x}}: \mathrm{H}$ deposition and patterning; (e) deposition of titanium studs; (f) dry etching of the sacrificial polyimide layer.

Then, spin-on glass (SOG) 700B diluted in water at 50\% was deposited on the wafer and cured at $250{ }^{\circ} \mathrm{C}$ for $2 \mathrm{~h}$ in air to obtain a layer with a refractive index $n=1.462$ and a thickness of $180 \mathrm{~nm}$ that helps to planarize the surface. A refractive index close to that of thermal $\mathrm{SiO}_{2}$ assures a dense film with a low number of voids and defects. We avoided a thicker layer of SOG due to cracking and peeling issues by adding a second dielectric $120 \mathrm{~nm}$-thick silicon nitride $\left(\mathrm{SiN}_{\mathrm{x}}\right)$ layer by PECVD. All film depositions by PECVD were performed in a system working at $110 \mathrm{kHz}$ and $200{ }^{\circ} \mathrm{C}$.

After that, a second $\mathrm{Al}$ metal layer with a thickness of $600 \mathrm{~nm}$ was evaporated and patterned by liftoff. The first $\mathrm{Al}$ layer defined the columns and the second layer defined the rows and the reflective mirror. Then, a $50 \mathrm{~nm}$-thick $\mathrm{SiN}_{\mathrm{x}}$ layer was deposited by PECVD to protect the aluminum pads from a later step of wet etching. A layer of polyimide (PI-2610) was spin-coated on the silicon wafer to form a $2.5 \mu \mathrm{m}$-thick gap, as part of a resonant quarter-wavelength cavity to improve absorption in the LWIR band. This Fabry-Perot resonant cavity was tuned at $10 \mu \mathrm{m}$ wavelength by adjusting polyimide thickness $\mathrm{d}$ according to the relation $d=\lambda / 4 n+\mathrm{N} \lambda / 2 n$, where $\mathrm{N}=0,1,2, \ldots$ and $n$ is the refractive index of the vacuum (after polyimide removal). Polyimide was soft-backed in a nitrogen environment with a ramp of $5{ }^{\circ} \mathrm{C} / \mathrm{min}$ and finally cured at $250^{\circ} \mathrm{C}$ for $2 \mathrm{~h}$ in fresh air to avoid the formation of bubbles.

A hard Al mask, $150 \mathrm{~nm}$ thick, was evaporated and patterned by wet etching; the polyimide was then patterned with oxygen plasma by reactive ion etching (RIE) using an AME-8110 tool from Applied Materials, Inc., Santa Clara, CA, USA, in order to open contact windows. After that, Al-etch solution was employed to remove the aluminum hard mask. The following step consisted of patterning the $\mathrm{SiN}_{\mathrm{x}}$ and $\mathrm{SOG}$ layers through the contact windows using $\mathrm{CF}_{4}$-based plasma with a micro-RIE series 800 reactor from Technics. Then, the thermosensing film $400 \mathrm{~nm}$ thick was deposited as described earlier (Section 2.1). In order to shape the membranes, the $\mathrm{CF}_{4}$ plasma was employed to pattern the pm-Si $\mathrm{Ge}_{1-\mathrm{x}}: \mathrm{H}$ film by the RIE technique.

After that, a $600 \mathrm{~nm}$-thick Ti layer was evaporated and patterned by liftoff to create supporting studs. This structure thermally isolates the membrane from the substrate. Furthermore, Ti has a low thermal conductivity of $21.9 \mathrm{~W} / \mathrm{m} \cdot \mathrm{K}$ and is a material commonly used in the Si-CMOS process. Finally, the silicon wafer was diced and the polyimide sacrificial layer was removed by oxygen plasma using a barrel asher L2101 from Branson/IPC, Hayward, CA, USA.

\subsection{Experimental Setup}

To perform the characterization, a single die with an array of $19 \times 20$ elements was placed in a DIP-40 package from Kyocera Corporation, Kyoto, Japan and bonded with gold wires. Microbolometers were then mounted inside a vacuum chamber MTD-150 from Lake Shore Cryotronics, Inc., Westerville, $\mathrm{OH}$, USA (Figure 3). It was evacuated to 20 mTorr and measurements were carried out at $300 \mathrm{~K}$. 
For voltage responsivity $\left(\mathfrak{R}_{v}\right)$ measurements, the array was illuminated with a cavity blackbody radiator using a silicon carbide ( $\mathrm{SiC}$ ) rod from Kanthal Globar as a broadband infrared source. Radiation comes out through a one inch aperture, which was then modulated at $30 \mathrm{~Hz}$ with a chopper wheel SR540 from Stanford Research Systems, Sunnyvale, OH, USA.

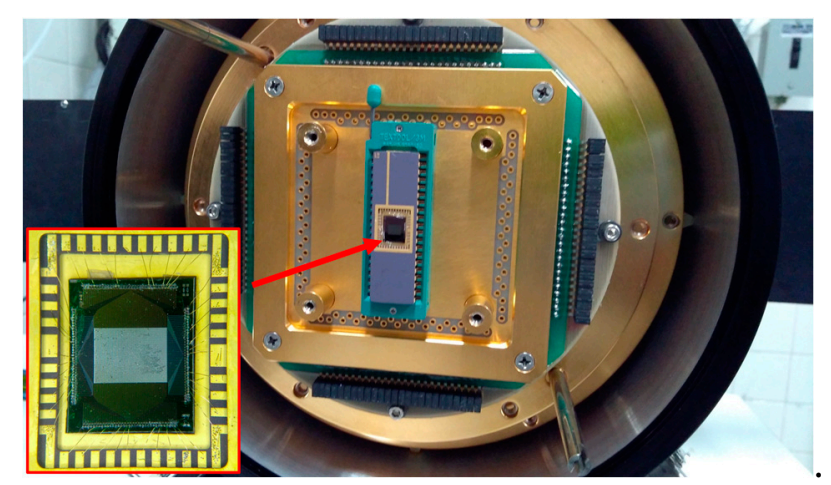

Figure 3. Array of microbolometers wire-bonded to a DIP-40 package and mounted inside the vacuum chamber.

Modulated radiation was then passed through a flat window of zinc selenide (ZnSe) with transmittance of $70 \%$ in the range of $0.6-20 \mu \mathrm{m}$, followed by placement of a $260 \mu \mathrm{m}$-thick silicon lid in front of the package. The incident radiation power was measured with an Oriel 71968 thermopile. A DC current of $70 \mu \mathrm{A}$ was set across each microbolometer through a metal load resistor of $15 \mathrm{k} \Omega$ by using a SourceMeter-2400 from Keithley. The resistor value was very close to that of most measured bolometers. Voltage output was routed to a low noise amplifier LMC6482, from Texas Instruments, Inc., Dallas, TX, USA, configured as voltage follower and powered with batteries. Then, the output was connected to an oscilloscope; Figure 4 a shows the setup employed. Noise measurements were performed in dark conditions at $300 \mathrm{~K}$, and as before, a DC current of $70 \mu \mathrm{A}$ was set. In addition, the vacuum inside the chamber was kept at 20 mTorr. The voltage signal was routed to a lock-in amplifier SR530 from Stanford Research Systems, as shown in Figure 4b. A reference signal of $30 \mathrm{~Hz}$ was provided from a signal generator, while measurements were performed with a bandwidth $(\Delta f)$ of $1 \mathrm{~Hz}$.

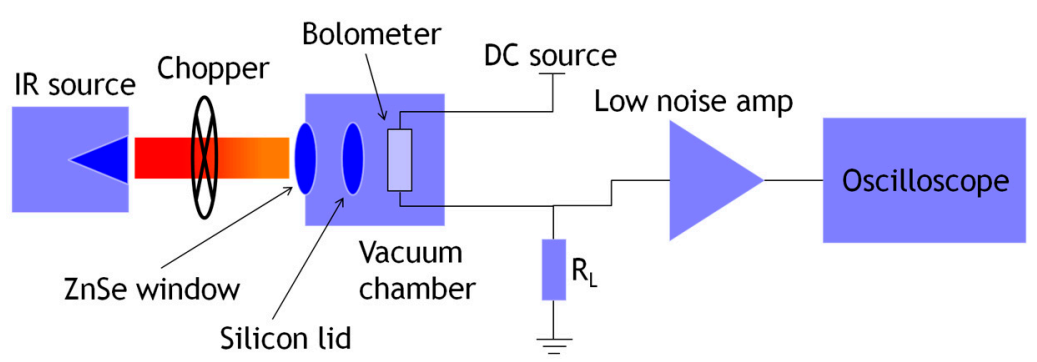

(a)

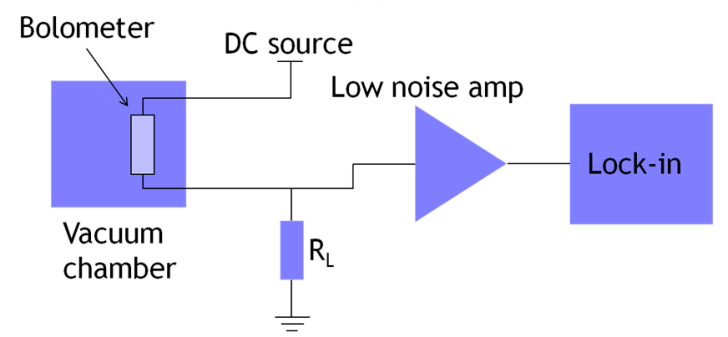

(b)

Figure 4. Experimental setup for (a) responsivity and (b) noise measurement. 


\section{Results}

A scanning electron microscope (SEM) picture of a section of the microbolometer array is shown in Figure 5 a, while Figure 5 b shows an image of one $50 \times 50 \mu \mathrm{m}^{2}$ microbolometer. A close inspection shows a slight buckling of the membrane due to residual stress in the pm-Si $\mathrm{x}_{\mathrm{x}} \mathrm{e}_{1-\mathrm{x}}: \mathrm{H}$; however, it is also observed that the microbolometers in the array are in structurally good condition.

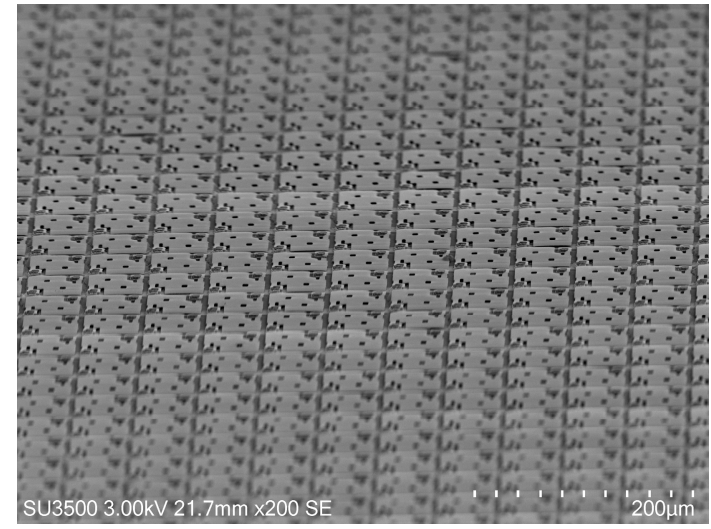

(a)

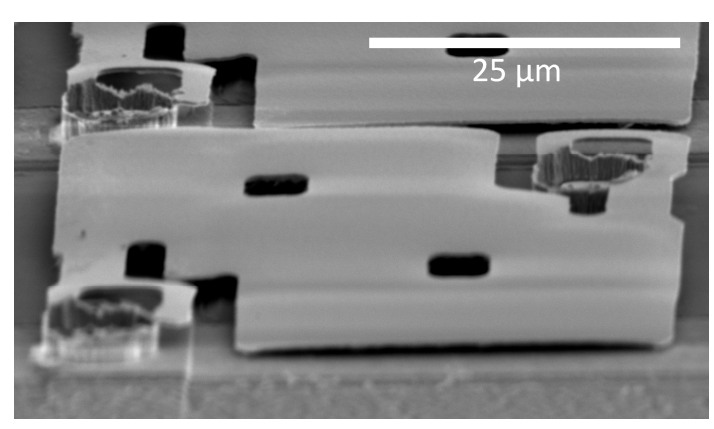

(b)

Figure 5. (a) SEM image of a part of the microbolometer array. (b) SEM image of one $50 \times$ $50 \mu \mathrm{m}^{2}$ microbolometer.

Voltage responsivity $\left(\mathfrak{R}_{v}\right)$ was experimentally calculated in each microbolometer using Equation (4), where $\Delta V$ was the voltage output in response to the infrared signal $P_{\text {in }}$ irradiated to the microbolometer, calculated as $4.84 \times 10^{-7} \mathrm{~W}$ from measurements of the thermopile and the device's area. A maximum $\mathfrak{R}_{v}$ of $4 \times 10^{4} \mathrm{~V} / \mathrm{W}$ at $30 \mathrm{~Hz}$ chopper frequency was found.

$$
\mathfrak{R}_{V}=\frac{\Delta V}{P_{\text {in }}}
$$

Noise in microbolometers was calculated using Equation (5), where $V_{n B o l+S y s t e m}$ is the root mean square (rms) noise of the bolometer plus the rms noise of the system, while $V_{n S y s t e m}$ is the rms noise of the setup without the contribution of the microbolometer. $V_{n \text { System }}$ was found to be $32.8 \mathrm{nV} / \mathrm{Hz}^{1 / 2}$, and the noise in microbolometers was in the range $2-35 \mu \mathrm{V} / \mathrm{Hz}^{1 / 2}$.

$$
\left(\overline{V_{n B o l}}\right)^{2}=\left(\overline{V_{n B o l+S y s t e m}}\right)^{2}-\left(\overline{V_{n S y s t e m}}\right)^{2}
$$

Specific detectivity $\left(D^{*}\right)$ was then calculated with Equation (6) using data from the responsivity and noise measurements, where $A$ is the effective area of the microbolometer, which was $2.046 \times$ $10^{-5} \mathrm{~cm}^{2}$, and $\Delta f$ is the bandwidth, equal to $1 \mathrm{~Hz}$. Detectivity is a signal-to-noise ratio normalized to the area of the detector, thus it can be used to compare performance between different types of detectors.

$$
D *=\frac{\mathfrak{k}_{V} \sqrt{A \Delta f}}{\overline{V_{n B o l}}} .
$$

A detectivity map of the 380 measured devices is shown in Figure 6. A maximum $D^{*}$ was found to be $2 \times 10^{7} \mathrm{~cm} \cdot \mathrm{Hz}^{1 / 2} / \mathrm{W}$, while the minimum was approximately $0.2 \times 10^{7} \mathrm{~cm} \cdot \mathrm{Hz}^{1 / 2} / \mathrm{W}$. Furthermore, it was observed that all devices responded to infrared radiation, which is a consequence of the structural integrity of all the microbolometers in the array. This is of major importance since the percentage of damaged pixels in a commercial array is in the order of $1 \%$ [32]. The performance of the pm-Si $\mathrm{Ge}_{1-\mathrm{x}}: \mathrm{H}$ film implemented on a $19 \times 20$ microbolometer array serves as a proof-of-concept to assess its application on commercial devices. This material is an ideal candidate to reduce manufacturing cost as it can be 
readily integrated with CMOS back-end-of-the-line processes and ultimately to be applied in detectors of low-cost and high-volume markets [33].

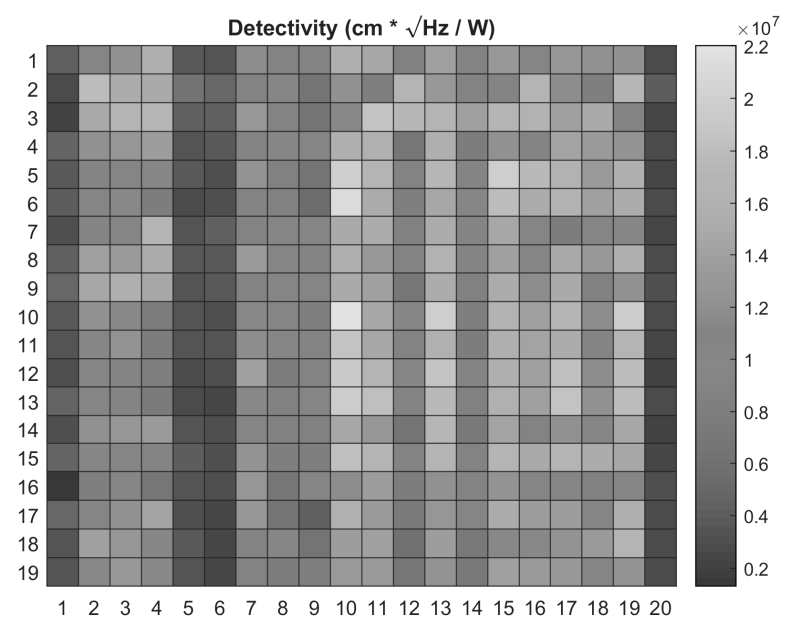

Figure 6. Detectivity map of the microbolometer array.

In addition, we calculated the noise equivalent power (NEP) with Equation (7), which represents the amount of absorbed radiation power that gives a signal equal to the total rms noise. In terms of bolometer performance, the lower the NEP the better. Of all the analyzed devices, a minimum value of $2 \times 10^{-10} \mathrm{~W} / \mathrm{Hz}^{1 / 2}$ was found.

$$
N E P=\frac{\overline{V_{n B o l}}}{\mathfrak{R}_{V}} .
$$

Statistical analysis showed a mean detectivity $(\mu)$ of $1.063 \times 10^{7} \mathrm{~cm} \cdot \mathrm{Hz}^{1 / 2} / \mathrm{W}$ with a standard deviation $(\sigma)$ of $4.75 \times 10^{6} \mathrm{~cm} \cdot \mathrm{Hz}^{1 / 2} / \mathrm{W}$. The histogram of the detectivity values is shown in Figure 7 , where Gaussian behavior was observed, which is commonly found in microbolometer arrays. However, a second Gaussian was also observed at lower $D^{*}$ values, which was a possible consequence of the stress presented in some microbolometers, causing a thermal flow to the substrate and thus a reduction of $D^{*}$. Although a large standard deviation value is not desirable, it is important to stress that all devices showed a response under infrared radiation. The reduction of residual stress is a subject outside the scope of the present work; however, we achieved promising results with thermal treatments with temperatures as low as $200{ }^{\circ} \mathrm{C}$.

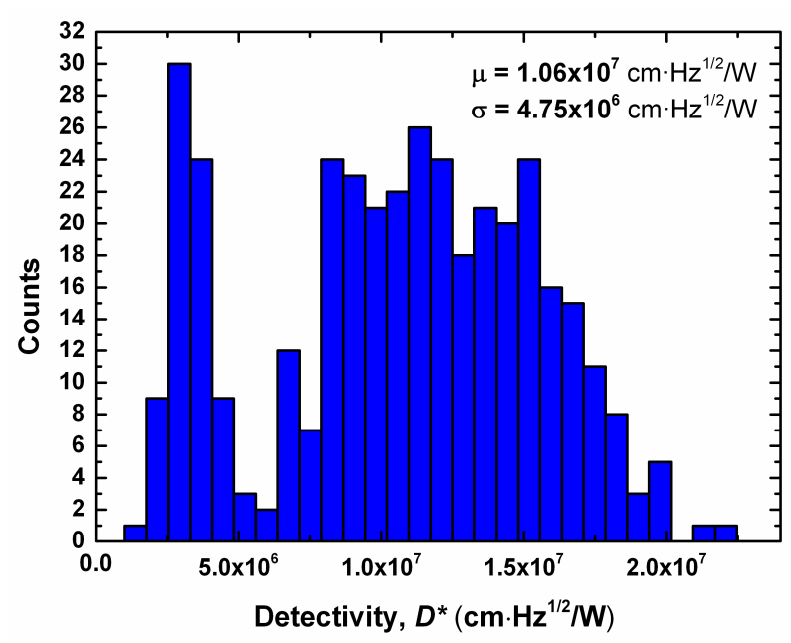

Figure 7. Histogram of the detectivity distribution in the microbolometer array. 
In order to compare the performance of $\mathrm{pm}-\mathrm{Si}_{\mathrm{x}} \mathrm{Ge}_{1-\mathrm{x}}: \mathrm{H}$ microbolometers with similar devices, Table 2 provides data for sensors having different thermosensing materials. First, we have a new approach to increase TCR by thermal annealing at $300{ }^{\circ} \mathrm{C}$ of a multilayer structure of $\mathrm{VO}_{\mathrm{x}} / \mathrm{ZnO}$. Here, detectivity in the order of $10^{7} \mathrm{~cm} \cdot \mathrm{Hz}^{1 / 2} / \mathrm{W}$ is achieved; however, this material lacks CMOS compatibility. In the same way, the device with an active layer of $\mathrm{VO}_{x}$ requires thermal annealing at $300{ }^{\circ} \mathrm{C}$ to obtain a low noise level; this results in a $D^{*}$ value in the order of $10^{7} \mathrm{~cm} \cdot \mathrm{Hz}{ }^{1 / 2} / \mathrm{W}$ and low bolometer resistance $\left(200 \mathrm{k} \Omega\right.$ ). Once again, this $\mathrm{VO}_{\mathrm{x}}$ microbolometer cannot be integrated into a standard $\mathrm{Si}-\mathrm{CMOS}$ process. The amorphous silicon (a-Si:H) active film device has an innovative pixel-level packaging, yet it has serious impedance problems due to the extensive number of manufacturing steps. This is reflected in a noise level that directly affects $D^{*}$ with a low value of $10^{6} \mathrm{~cm} \cdot \mathrm{Hz}^{1 / 2} / \mathrm{W}$. Nevertheless, this device boosts the current trend towards silicon-based microbolometers. Finally, a poly-SiGe device with a good balance between noise and TCR results in a high detectivity value of $10^{9} \mathrm{~cm} \cdot \mathrm{Hz} / 2 / \mathrm{W}$; despite being a material compatible with CMOS technology, it requires a crystallization process higher than $600{ }^{\circ} \mathrm{C}$, which introduces serious thermal constraints.

Table 2. Comparison of $\mathrm{pm}-\mathrm{Si}_{\mathrm{x}} \mathrm{Ge}_{1-\mathrm{x}}: \mathrm{H}$ microbolometer performance with other devices at $30 \mathrm{~Hz}$.

\begin{tabular}{lccccc}
\hline Material & $\begin{array}{c}\text { pm-Si }_{\mathbf{x}} \mathrm{Ge}_{1-\mathbf{x}}: \mathbf{H} \\
\text { This Work }\end{array}$ & $\begin{array}{c}\mathbf{V O}_{\mathbf{x}} / \mathbf{Z n O} \\
{[34]}\end{array}$ & $\begin{array}{c}\text { a-Si:H } \\
{[35,36]}\end{array}$ & $\begin{array}{c}\text { VO }_{\mathbf{x}} \\
{[37]}\end{array}$ & $\begin{array}{c}\text { Poly-SiGe } \\
\text { [4] }\end{array}$ \\
\hline Size $\left(\mu \mathrm{m}^{2}\right)$ & $50 \times 50$ & $50 \times 50$ & $35 \times 35$ & $25 \times 25$ & $50 \times 50$ \\
$\boldsymbol{R}_{v}(\mathrm{~V} / \mathrm{W})$ & $2 \times 10^{4}$ & $2 \times 10^{4}$ & $3.7 \times 10^{3}$ & $2.44 \times 10^{5}$ & $1.64 \times 10^{4}$ \\
$\mathbf{N E P}\left(\mathrm{W} / \mathrm{Hz}^{1 / 2}\right)$ & $2 \times 10^{-10}$ & $1 \times 10^{-10}$ & $7.7 \times 10^{-10}$ & $1.4 \times$ & $6 \times 10^{-10}$ \\
& & & & $10^{-10}$ & \\
$\mathbf{D}^{*}\left(\mathrm{~cm} \cdot \mathrm{Hz}^{1 / 2} / \mathrm{W}\right)$ & $2 \times 10^{7}$ & $4 \times 10^{7}$ & $4.5 \times 10^{6}$ & $1.55 \times 10^{7}$ & $2.26 \times 10^{9}$ \\
TCR $(\% / \mathrm{K})$ & 4.08 & 3.12 & 2.27 & 2.6 & 0.68 \\
$\mathbf{R}(\Omega)$ & $15 \times 10^{3}$ & - & $200 \times 10^{9}$ & $200 \times 10^{3}$ & $10 \times 10^{3}$ \\
\hline
\end{tabular}

Here we have presented the advantages of taking a material compatible with CMOS processes such as a-Si:H and improving it to obtain better performance. However, having a high TCR value is not enough, it is also necessary to optimize other properties such as noise and residual stress. In our case, it is probable that the low level of $\mathfrak{R}_{v}$ is the consequence of a thermal leak towards the substrate due to the bending of the membranes.

\section{Conclusions}

An array of $19 \times 20$ microbolometers made of $p m-\mathrm{Si}_{x} \mathrm{Ge}_{1-\mathrm{x}}: \mathrm{H}$ was fabricated and tested. A thermosensing film with a TCR of $4.08 \% / \mathrm{K}$ was employed and microbolometers showed a low resistance of about $15 \mathrm{k} \Omega$. Noise was found to be in acceptable range of values $\left(\mu \mathrm{V} / \mathrm{Hz}^{1 / 2}\right)$, but responsivity was low, about $1 \times 10^{4} \mathrm{~V} / \mathrm{W}$, and detrimental to detectivity, which achieved values in a range near $1 \times 10^{7} \mathrm{~cm} \cdot \mathrm{Hz}^{1 / 2} / \mathrm{W}$ at $30 \mathrm{~Hz}$ of chopper frequency. Finally, we found an exceptional operability of $100 \%$ of the pixels tested and the minimum NEP was $2 \times 10^{-10} \mathrm{~W} / \mathrm{Hz}^{1 / 2}$. Improvements in the performance of the devices for both detectivity and spatial uniformity are in progress.

Author Contributions: Conceptualization, R.J., M.M., and A.T.; methodology, R.J. and M.M.; investigation, R.J., M.M., and A.T.; writing — original draft preparation, R.J. and M.M.; writing-review and editing, M.M., A.T., and A.P.; supervision, A.M., A.P., D.F., J.R.-M., J.C.-R., J.H.-P., and E.C.; project administration, M.M. and A.T. All authors have read and agreed to the published version of the manuscript.

Funding: This research received no external funding.

Acknowledgments: Authors thank the support from Conacyt-Fomix PUE-2018-03-02-84557 and Conacyt-Ciencia Basica 35309.

Conflicts of Interest: The authors declare no conflict of interest. 


\section{References}

1. Narita, K.; Kuribayashi, R.; Altintas, E.; Someya, H.; Tsuda, K.; Ohashi, K.; Tabuchi, T.; Okubo, S.; Imazato, M.; Komatsubara, S. A plastic-based bolometer array sensor using carbon nanotubes for low-cost infrared imaging devices. Sens. Actuators A Phys. 2013, 195, 142-147. [CrossRef]

2. Liger, M.; Tai, Y.-C. A $32 * 32$ Parylene-pyrolyzed carbon bolometer imager. In Proceedings of the 19th IEEE International Conference on Micro Electro Mechanical Systems, Istanbul, Turkey, 22-26 January 2006; pp. 106-109.

3. Håkansson, A.; Shahi, M.; Brill, J.W.; Fabiano, S.; Crispin, X. Conducting-polymer bolometers for low-cost IR-detection systems. Adv. Electron. Mater. 2019, 5, 1-7. [CrossRef]

4. Sedky, S.; Fiorini, P.; Baert, K.; Hermans, L.; Mertens, R. Characterization and optimization of infrared poly SiGe bolometers. IEEE Trans. Electron Devices 1999, 46, 675-682. [CrossRef]

5. Gray, J.; Çelik-Butler, Z.; Butler, D. MgO sacrificial layer for micromachining uncooled Y-Ba-Cu-O IR microbolometers on Si/sub 3/N/sub 4/ bridges. J. Microelectromech. Syst. 1999, 8, 192-199. [CrossRef]

6. Yoneoka, S.; Liger, M.; Yama, G.; Schuster, R.; Purkl, F.; Provine, J.; Prinz, F.B.; Howe, R.T.; Kenny, T.W. ALD-metal uncooled bolometer. In Proceedings of the IEEE 24th International Conference on Micro Electro Mechanical Systems, Cancun, Mexico, 23-27 January 2011; pp. 676-679.

7. Saxena, R.; Bhan, R.; Rana, P.S.; Vishwakarma, A.; Aggarwal, A.; Khurana, K.; Gupta, S. Study of performance degradation in Titanium microbolometer IR detectors due to elevated heating. Infrared Phys. Technol. 2011, 54, 343-352. [CrossRef]

8. Tanaka, A.; Matsumoto, S.; Tsukamoto, N.; Itoh, S.; Chiba, K.; Endoh, T.; Nakazato, A.; Okuyama, K.; Kumazawa, Y.; Hijikawa, M.; et al. Influence of bias heating on a titanium bolometer infrared sensor. AeroSense 1997, 3061, 198-209. [CrossRef]

9. Tanrikulu, M.Y.; Okyay, A.K.; Yildizak, C.; Akin, T.; Akar, O.; Sarac, A. Single layer microbolometer detector pixel using ZnO material. Infrared Technol. Appl. 2018, 10624, 1062417. [CrossRef]

10. Pope, T.D.; Jerominek, H.; Alain, C.; Cayer, F.; Tremblay, B.; Grenier, C.; Topart, P.A.; LeClair, S.; Picard, F.; Larouche, C.; et al. Commercial and custom 160x120, 256x1, and 512x3 pixel bolometric FPAs. AeroSense 2002, 4721, 64-75. [CrossRef]

11. Li, C.; Skidmore, G.D.; Han, C.J. Uncooled VOx infrared sensor development and application. SPIE Def. Secur. Sens. 2011, 8012, 80121. [CrossRef]

12. Wang, B.; Lai, J.; Li, H.; Hu, H.; Chen, S. Nanostructured vanadium oxide thin film with high TCR at room temperature for microbolometer. Infrared Phys. Technol. 2013, 57, 8-13. [CrossRef]

13. Riou, O.; Logerais, P.-O.; Durastanti, J.F. Quantitative study of the temperature dependence of normal LWIR apparent emissivity. Infrared Phys. Technol. 2013, 60, 244-250. [CrossRef]

14. Han, M.-S.; Kim, D.H.; Ko, H.-J.; Shin, J.C. A fabrication and characterictics of microbolometer detectors using VOx/ZnO/VOx multilayer thin film processing. SPIE Def. Secur. 2014, 9070, 90701. [CrossRef]

15. Grayli, S.V.; El-Chami, I.; Bahreyni, B.; Leach, G. Room temperature deposition of highly sensitive vanadium oxide films for infrared light sensing applications. In Proceedings of the IEEE Sensors, Busan, South Korea, 1-4 November 2015; pp. 1-4.

16. Gu, D.; Zhou, X.; Guo, R.; Wang, Z.; Jiang, Y. The microstructures and electrical properties of Y-doped amorphous vanadium oxide thin films. Infrared Phys. Technol. 2017, 81, 64-68. [CrossRef]

17. Ahmed, A.H.Z.; Tait, R.N.; Oogarah, T.B.; Liu, H.C.; Denhoff, M.W.; Sproule, G.; Graham, M. A surface micromachined amorphous GexSi1-xOy bolometer for thermal imaging applications. In Proceedings of the Photonic Applications in Astronomy, Biomedicine, Imaging, Materials Processing, and Education, Ottawa, ON, Canada, 26-29 September 2004; Volume 5578, pp. 298-309.

18. Schimert, T.; Brady, J.; Fagan, T.; Taylor, M.; McCardel, W.; Gooch, R.; Ajmera, S.; Hanson, C.; Syllaios, A.J. Amorphous silicon based large format uncooled FPA microbolometer technology. Infrared Technol. Appl. 2008, 6940, 694023. [CrossRef]

19. Ajmera, S.; Brady, J.; Hanson, C.; Schimert, T.; Syllaios, A.J.; Taylor, M. Performance improvement in amorphous silicon based uncooled microbolometers through pixel design and materials development. Infrared Technol. Appl. 2011, 8012, 80121. [CrossRef]

20. Tissot, J.L.; Robert, P.; Crastes, A.; Tinnes, S.; Bercier, E.; Durand, A. Status of uncooled infrared detector technology at ULIS, France. Def. Sci. J. 2013, 63, 545-549. [CrossRef] 
21. Zhou, T.; Zuo, Y.; Qiu, K.; Zheng, J.; Wang, Q. Potential of Ti doped hydrogenated amorphous Si film with suitable resistivity and high TCR for microbolometer applications. Vacuum 2015, 119, 30-33. [CrossRef]

22. Su, J.-H.; Yeh, W.-K.; Chang, W.-T.; Wu, B.-L.; Lu, J.-M.; Wang, J.-H.; Fang, Y.-K.; Chen, P.-Y. Temperature coefficient of resistance related to amorphous silicon/metal contact design of microbolometers. In Proceedings of the 3rd International Conference on Devices, Circuits and Systems (ICDCS), Coimbatore, India, 3-5 March 2016; pp. 63-67.

23. Moreno, M.; Torres, A.; Calleja, C.; Lázaro, R.C.A.; Rosales, P.; Kosarev, A.; Jiménez-Zavala, R. Exploring the infrared-sensing properties of polymorphous silicon-germanium (pm-SixGey:H) thin films. Can. J. Phys. 2014, 92, 565-569. [CrossRef]

24. Bronner, W.; Kleider, J.; Brüggemann, R.; Cabarrocas, P.R.I.; Mencaraglia, D.; Mehring, M. Comparison of transport and defects properties in hydrogenated polymorphous and amorphous silicon. J. Non-Cryst. Solids 2002, 299, 551-555. [CrossRef]

25. Kim, K.; Johnson, E.; Abramov, A.; Cabarrocas, P.R.I. Light induced electrical and macroscopic changes in hydrogenated polymorphous silicon solar cells. EPJ Photovolt. 2012, 3, 30301. [CrossRef]

26. Chou, Y.-P.; Lee, S.-C. Structural, optical, and electrical properties of hydrogenated amorphous silicon germanium alloys. J. Appl. Phys. 1998, 83, 4111-4123. [CrossRef]

27. Jiménez-Zavala, R.; Moreno, M.; Torres, A.; Rosales, P.; Gomez, V.; Carlos, N.; Cabarrocas, P.R.I. Effect of Pressure and Flow Rates on Polymorphous Silicon-Germanium (pm-Six Ge1-x:H) Thin Films for Infrared Detection Applications. Phys. Status Solidi A 2018, 215, 1700735. [CrossRef]

28. Moreno, M.; Jiménez-Zavala, R.; Torres, A.; Lázaro, R.C.A. Microbolometers based on amorphous silicon-germanium films with embedded nanocrystals. IEEE Trans. Electron Devices 2015, 62, 2120-2127. [CrossRef]

29. Jiménez-Zavala, R.; Moreno, M.; Torres, A.; Rosales, P.; Sanz-Pascual, M.T.; Lázaro, R.C.A. Performance characterization of infrared detectors based on polymorphous silicon-germanium (pm-Six Ge1-x:H) thin films deposited at low temperature. Phys. Status Solidi A 2018, 215, 1700736. [CrossRef]

30. Cabarrocas, P.R.I.; Chaâbane, N.; Kharchenko, A.V.; Tchakarov, S. Polymorphous silicon thin films produced in dusty plasmas: Application to solar cells. Plasma Phys. Control. Fusion 2004, 46, B235-B243. [CrossRef]

31. Tanielian, M. Adsorbate effects on the electrical conductance of a-Si: H. Philos. Mag. B 1982, 45, 435-462. [CrossRef]

32. Budzier, H.; Gerlach, G. Calibration of uncooled thermal infrared cameras. J. Sens. Sens. Syst. 2015, 4, 187-197. [CrossRef]

33. Liddiard, K.C. Application of mosaic pixel microbolometer technology to very high-performance, low-cost thermography and pedestrian detection. SPIE Def. Secur. Sens. 2013, 8704, 87043. [CrossRef]

34. Han, M.-S.; Kim, D.H.; Ko, H.J.; Kim, H. Vanadium oxide microbolometer using ZnO sandwich layer. Appl. Sci. Converg. Technol. 2015, 24, 178-183. [CrossRef]

35. Ahmed, M.; Butler, D.P.; Celik-Butler, Z. Device-level vacuum packaged uncooled microbolometer on a polyimide substrate. Infrared Phys. Technol. 2016, 79, 50-57. [CrossRef]

36. Ahmed, M.; Chitteboyina, M.M.; Butler, D.P.; Celik-Butler, Z. Temperature sensor in a flexible substrate. IEEE Sens. J. 2011, 12, 864-869. [CrossRef]

37. Abdel-Rahman, M.; Al-Khalli, N.; Zia, M.F.; Alduraibi, M.; Ilahi, B.; Debbar, N.; Awad, E. Fabrication and design of vanadium oxide microbolometer. In Proceedings of the 6th International Advances in Applied Physics and Materials Science Congress \& Exhibition, Istanbul, Turkey, 1-3 June 2016; Volume 1809, p. 20001.

(C) 2020 by the authors. Licensee MDPI, Basel, Switzerland. This article is an open access article distributed under the terms and conditions of the Creative Commons Attribution (CC BY) license (http://creativecommons.org/licenses/by/4.0/). 